\title{
Association Between the Use of Active Learning Strategies and Classroom Engagement Among Nursing Students
}

\author{
Anam Mohi-ud-Din Muhammad Hussain Muhammad Afzal Syed Amir Gillani \\ Lahore School of Nursing, The University of Lahore, Pakistan
}

\begin{abstract}
Background: Learning is a whole life process which requires an appropriate learning environment. Research indicated that a number of different factors influence the student's engagement in learning process. One of the most important factors is the use of active learning strategies in classroom environment. Active learning activities such as power point presentation, simulation, role play, case studies, reflection on learning and discussion enhance students meaningful processing, participation and focused attention. Active learning activities can be used to improve students learning outcomes through engaging them in learning process. Objective: The objective of the current study is to assess the association between the use of active learning strategies and classroom engagement among nursing students of The University of Lahore. Methods: A descriptive, correlational study was conducted on 117 nursing students of the University of Lahore. Participants were selected through convenient sampling technique. The data was collected through adopted questionnaire and analyzed on SPSS using descriptive and inferential statistics. Results: According to analysis of study, p value was .015 and Pearson correlation value of active learning strategies and nursing students' engagement was .225. It indicates that there is significant positive association between the use of active learning strategies and classroom engagement of nursing students ( $\mathrm{r}=.225$, $\mathrm{p}<0.05)$. Conclusions: Active learning strategies and student's perception of active leaning in classroom has positive relationship with Classroom engagement of nursing students. Therefore, active learning strategies can be used in improving and enhancing the engagement of nursing students.
\end{abstract}

Keywords: Active Learning Strategies, Classroom Engagement, Nursing Students

DOI: $10.7176 / \mathrm{JHMN} / 62-08$

Publication date:May $31^{\text {st }} 2019$

\section{Introduction}

Learning is a continuous whole life process. The teaching-learning process cannot take place in a vacuum. Therefore, an appropriate learning environment is compulsory which has a strong impact on students' learning experiences and outcomes in classroom (Malik \& Rizvi, 2018). There are a number of factors that influence upon the learning process and achievement of students in classroom settings. These include teacher, students, content, learning process, learning styles, strategies and learning situation. One of them is active learning strategies which play a crucial role to keep students engaged and allow them to become successful in an academic course (Miller \& Metz, 2014).

Active learning strategies are explained by Bonwell and Eison (1991) as those activities that occur inside the classrooms and involve learners. The most important aspect of active learning strategies is that it allows students to focus on what they are doing. There are a number of active learning strategies such as simulation, problembased learning, assignment making and presenting on power-point. When activities and sessions in the classrooms are made interactive, then it itself becomes a productive environment for the learners. It is also noticed that using active learning strategies such as role playing, group work, case studies class presentations leads to better learning with a student-centered approach (D’Souza, Isac, Venkatesaperumal, Nairy, \& Amirtharaj, 2014).

There are a range of methods of keeping students engaged and enriched in class rooms (Gregg \& Twibell, 2016). Students' perception of active learning in the classroom is of great importance. Students perceived that active learning is beneficial for their learning. Researches shows that students also stated that active learning has improved their understanding of course material and they feel comfortable with these teaching learning strategies (Miller \& Metz, 2014). Features of active learning strategies aid in involvement of learners in listening, encouragement to share their thoughts and values, and invitation to participate in higher level thinking rather than cramming (Bonwell and Eison, 1991 as cited by Rands \& Gansemer-Topf, 2017).

Engagement of nursing students is explained as the willingness and choice of the students to participate actively in the learning processes occurring in clinical settings such that it also leads to generation of tangible behaviors inside or outside the class or in the clinical environment (D'Souza et al., 2014). True engagement is one where the student is involved in three aspects: cognitive, emotional and behavioral while these three aspects lead to various other parts such as active participation in class, concentration on teamwork, cooperation and creative thinking (Hudson, 2015).

Meaningful processing, students' participation and attention in classroom is known as engagement. Meaningful processing is the interest of students in reflecting upon whatever they learn in the class and how they apply their learning in real life situations. Student participation is here defined as students being active or afraid 
for communication, discussion and asking questions in the classroom. Focused attention describes how much the students are attentive or bored in the class. In order to measure the nursing program quality as well as the students' success, student engagement can be considered as the measure of continued assessment. It is because of the fact that success of nursing programs directly relate to students' engagement and also links to the longevity to stay in profession after the graduation (Hampton \& Pearce, 2016).

Nursing teachers are responsible for providing best learning practices and to change course content to include active learning activities in an academic environment (Nabors, 2012 as cited bySharma, 2017). There are a range of methods of keeping students engaged and enriched in class rooms (Gregg \& Twibell, 2016). This can be obtained through engaging students within different academic activities. It is confirmed by a number of scholars that there is positive effect of active learning on outcomes of students' learning. It is also found that the education quality is influenced by a number of dimensions such as well-planned curriculum, better teaching methods and effective ways of implementing the curriculum (Abdullah \& Jong, 2014).

Students' engagement is affected deeply with a number of factors such as goals, active learning strategies, self-efficacy and most importantly student's motivation (Rocher, 2018). Effective implementation of active learning strategies through course has been linked to improvements in levels of students' engagement which ultimately has effects on the students' learning. (Oermann, 2015). When overall more students are engaged in learning through active learning environment, then overall academic achievements of that educational institution also raise. Hence, there is a positive influence of active learning strategies on students' engagement and academic success (Sattar, Kouar, \& Gillani, 2018).

\subsection{Aim of Study}

The aim of this study was to assess the association between the use of active learning strategies and classroom engagement among nursing students.

\subsection{Problem Statement}

It is observed that the academic performance of students has been declining in higher education institutions. It is because they are not using active learning strategies in the classroom to promote the engagement of nursing students (Cavanagh et al., 2018). Despite a strong empirical link between active learning strategies and students' engagement, less is known about factors leading to engagement in these contexts. On the other hand, discipline of nursing lack of co-relational studies that examine the actual personal involvement of the students when they are engaged in the creation of their own learning activities (Kirschner, 2015). In Pakistan, no published research was found in these contexts. Hence, there is a need to conduct research to explore the relationship of active learning strategies with the students' engagement in classroom environment.

\subsection{Significance of the Study}

There are multiple ways in which this research is significant for the nursing institutions. Through the current study, I'll be able to understand the relationship of active learning strategies with learning environment and students' engagement in classroom. The results of study will be helpful for the policy makers, nurse educators and educational institution. The study will significantly contribute to the nursing education literature in Pakistan. Findings of the study will reveal what are the most effective ways of enhancing students' engagement levels. It provides rationale to investigate the learning strategies that can be applied in Pakistan classroom environment to increase students' engagement. will help organizations to formulate such curriculum that promote the environment where learning is valued. This will be helpful for students to modify their own engagement with their learning environment and course in which they are enrolled that will improve their academic achievements.

\subsection{Conceptual Framework}

Conceptual model of this study is based on the Astin's theory of involvement that was published in 1994. This theory considers three elements as its core concept; input, environment and outcomes. Astin (1984) described input as the characteristics of students that are possessed by them before joining educational institution such as background, demographics and past learning experiences. Here students' demographics including gender, age, prior learning experience, last semester GPA and expected course grade are input. Environment is the experiences that occur to the student while in the educational institution. In my framework, environment refers to all those active learning strategies (power point presentations, assignments, participation in role play, case studies and simulation, tutoring other students, reflection, and discussion) and students' perception of classroom environment (comfortable and encouraging environment). Outcome is the end result in terms of knowledge, values, beliefs, skills, behaviors and characteristics of students after exposure to the educational institution environment. In my study, outcomes are behavioral engagement (participation), cognitive engagement (meaningful processing) and Psychological engagement (focused attention). The model is based on the involvement behaviors of students at the institution level but current study implements the same model on the classroom level (Astin 1984 as cited by 
D’Souza et al., 2014).

\section{Literature Review}

Nursing profession is a complex one as the students seeking this profession have to maintain high-quality services. Students in nursing field are assumed to be highly responsible for dedicated care and thus it is need of profession that the students must have participation and involvement in learning so that they can work better (Hudson, 2015). National Survey of Student Engagement (NSSE) measures active learning on the following grounds: presentation making, working with fellow students on classroom projects, asking questions and contributing through answers, working with fellow students on assignment outside classroom settings, teaching peers, working on a communitybased project and discussing course material with people outside class (Carr, Palmer, \& Hagel, 2015).

The response of students on the active learning activities is positive as they find activities to be challenging, meaningful and aligned to the learning goals. In a study conducted in Khyber Pakhtunkhwa (KPK) Pakistan to measure the active learning perception in students towards undergraduate degree program, it was found that $67.6 \%$ students considered utilization of active learning strategies in classroom as positive. Based on their positive perception of ALS, these students responded positively to motivation in class $(49.7 \%)$, promotion in critical thinking (55.5\%), enhancement of participation and engagement in class $(32.4 \%)$ and integration of theory into practice $(29.5 \%)$. Based on these results it is clear that ALS must be incorporated into classroom teaching methods (Ul Huda, Ali, Nanji, \& Cassum, 2016).

A study was conducted to explore nursing students' engagement in their learning environment. The results showed that by use of active learning strategies in classroom, students are positively engaged in domain of meaningful process. Classroom and clinical setting also play an important role in participation in discussions with peers and teachers to become a productive learner and professional. Findings also revealed that student have positive attitude in the behavioral engagement area (Sattar et al., 2018).

One of the fundamental components is selection of teaching strategies. In a qualitative study; conducted on influence of active learning on students' engagement, it was found that the design of the classroom also helps learners in positive learning behaviors. The study showed that classroom design helps students in achieving maximum level of learning when there are no barriers in the interaction between students and faculty and when the students are encouraged for increased engagement (Rands \& Gansemer-Topf, 2017).

In a meta-analysis of technology, mathematics, engineering and science courses, it was verified that students who get engaged only in lecture courses have 1.5 times higher likeliness to fail as compared to the students who are engaged in active learning. The researchers found that the scores of students in active learning courses are $6 \%$ higher than that in regular lecture course only (Freeman et al., 2014). Hence, academic success is closely related to active learning strategies. Researchers confirmed that main barriers for faculty for implementation of active learning strategies are lack of students' interest, delivering too much content in limited time and large class (Miller \& Metz, 2014).

One of the studies in domain of students' engagement conducted to understand the perceptions of students enrolled in the university course about the experience from engagement during class time. When strategies such as problem solving and active listening are practiced within the class, then it positively affects the overall students' engagement and attention when there is variation of these levels in the students. There is a significant mediating relationship of working on problems, taking notes, sitting in class front, active listening working on hard problems on perceived learning. It is confirmed that when the students are taking notes, solving problems or taking notes, then they are more engaged in learning than those who are not doing any of the mentioned acts (Shernof et al., 2017).

D’Souza, Isac, Venkatesaperumal, Nainy \& Amirtharaj (2014) stated that teachers play an important role in engaging the students in active learning. These researchers reported that teachers develop higher levels of engagement in students when they carry out presentations, discussions and debates. Such actions also lead to improvement in communication skills. From the results, it was also found that three sub-domains of engagement i.e. participation, meaningful processes and focused attention are affected as students were able to score high mean scores in all three of these aspects. Also, at the same time, nursing students reported better creative thinking, critical thinking and problem-solving skills. Highest mean score was in participation sub-domain as compared to that in meaningful processes and focused attention. Based on category of having siblings, it was found that students with siblings studying in university show higher levels of engagement through participation (relationship with other students, communication \& interpersonal skills, feedback to assist learning and group work), cognitive learning (adaptability and critical thinking) and focused attention (workload). Scores in domain of participation were higher in case of siblings in the university while focused attention (coherence to curriculum and assessment) and meaningful processes (computer literacy \& self-managed learning) were higher in case of students without siblings studying in the university, revealing that to surpass learning standards more attention has to be given on individual factors. It was also found that students give importance to faculty support and learning opportunities when showing inclination towards clinical skills (D’Souza et al., 2014). 
A study was conducted to investigate the relationship among trust, growth, active learning and student engagement in an undergraduate science course. Results revealed a consistent and strong relationship among trust, commitment to active learning, engagement, and final grades of students. Thus, the findings highlighted the importance of interactions between students and educators in contributing the commitment and engagement of students in active-learning classroom contexts (Cavanagh et al., 2018).

\section{Materials and Methods}

\subsection{Setting:}

The research was conducted in School of Nursing, The University of Lahore.

\subsection{Research Design}

A correlational, descriptive, cross sectional design was used in this study.

\subsection{Target Population}

All nursing students (male and female) who met the inclusion criteria in the selected setting participated in the study.

\subsection{Sampling}

117 nursing students were selected through convenient sampling technique by using Solving's formula (Akhtar, Hussain, Afzal, \& Gilani, 2018).

$\mathrm{N}=$ population $\mathrm{n}=$ Sample size $\mathrm{e}=$ margin of error

$\mathrm{n}=\mathrm{N} / 1+(\mathrm{N})(\mathrm{e}) 2$

$\mathrm{n}=166 / 1+(166)(0.05) 2$

$\mathrm{n}=166 / 1+(166)(0.0025)$

$\mathrm{n}=166 / 1+0.415$

$\mathrm{n}=166 / 1.415$

$\mathrm{n}=117$

\subsection{Research Instruement}

An adopted questionnaire was used after obtaining permission of the author. The questionnaire had three parts.

Part 1: Demographic characteristics:

This section consisted of students' characteristics and academic variables. The students' characteristics include age, gender and academic rank whereas grade point average, expected course grade and prior learning experience will be considered as academic variables.

Part II Active Learning Environments Scale (ALES):

ALES measured the independent variable which was the use of active learning strategies in the classroom as active learning, and reported student perceptions of active learning in the classroom. Eleven items reported the active learning activities in the course during the current semester. Two items measured on a 4 point Likert scale which reflect the overall students perceptions of active learning in the classroom (Popkess, 2010).

Part III: Adapted Engaged Learning Index (AELI).

The Adapted Engaged Learning Index (AELI) was the third section used to measure the dependent that was classroom engagement. The original tool consists of 15 -item. The responses of questions vary on a six- point Likert scale $(1=$ strongly disagree. $2=$ moderately disagree, $3=$ mild disagree, 4 mild agree, $5=$ moderately agree and $6=$ strongly agree). Student engagement was measured in three dimensions. Three dimensions or subdomains of engagement of students were meaningful processing ( 9 items); demonstrating participation in the classroom ( 3 items) and focused attention (3 items) on the Adapted Engaged Learning Index (Popkess, 2010).

\subsection{Data Gathering and Data Analysis Procedure}

Data was collected by distributing close-ended questionnaire among nursing students of The University of Lahore. Data was analysed through Statistical Package for the social science (SPSS), 21 version. Descriptive statistics was used to analyse demographic data and inferential statistics was used to analyse the relationship between variables.

\subsection{Ethical Considerations}

Permission was obtained from IRB (Institutional Review Board) of The University of Lahore. A written consent was obtained from the participants which was attached with each questionnaire. The data kept confidential and participants had right to leave the study at any time without any penalty.

\section{Results}

The demographic characteristics of 117 subjects are shown in table 4.1. 


\begin{tabular}{|c|c|c|c|}
\hline \multirow[t]{2}{*}{ Characteristics } & \multirow[t]{2}{*}{ Category } & \multicolumn{2}{|c|}{ Respondents } \\
\hline & & Number & Percent \\
\hline \multirow{2}{*}{ Gender } & Male & 26 & 22.2 \\
\hline & Female & 91 & 77.8 \\
\hline \multirow{4}{*}{ Age } & $16-20$ years & 8 & 6.8 \\
\hline & $21-25$ years & 49 & 41.9 \\
\hline & $26-30$ years & 50 & 42.7 \\
\hline & $31-35$ years & 10 & 8.5 \\
\hline \multirow{4}{*}{ Prior Learning Experience } & F.A/F.Sc. & 48 & 41.0 \\
\hline & B.A/B.Sc. & 6 & 5.1 \\
\hline & M.A/M.Sc. & 1 & .9 \\
\hline & Diploma in Nursing & 62 & 53.0 \\
\hline \multirow{2}{*}{ Academic Rank } & BSN & 55 & 47.0 \\
\hline & Post RN-BSN & 62 & 53.0 \\
\hline \multirow{4}{*}{ Last Semester GPA } & $2.1-2.5$ & 4 & 3.4 \\
\hline & $2.6-3.0$ & 39 & 33.3 \\
\hline & $3.1-3.5$ & 56 & 47.9 \\
\hline & $3.6-4.0$ & 18 & 15.4 \\
\hline \multirow{3}{*}{ Expected Grade } & $\mathrm{A}$ & 28 & 23.9 \\
\hline & $\mathrm{B}$ & 66 & 56.4 \\
\hline & $\mathrm{C}$ & 23 & 19.7 \\
\hline Total & & 114 & 100 \\
\hline
\end{tabular}

Table 4.3 Association between ALES and AELI Scale

\begin{tabular}{|l|l|l|l|}
\hline \multicolumn{2}{|c|}{ Variables } & AL & SE \\
\hline Active Learning Strategies & Pearson Correlation & 1 & $.225^{*}$ \\
\cline { 2 - 4 } & Sig. (2-tailed) & & .015 \\
\cline { 2 - 4 } & N & 117 & 117 \\
\hline \multirow{3}{*}{ Students Engagement } & Pearson Correlation & $.225^{*}$ & 1 \\
\cline { 2 - 4 } & Sig. (2-tailed) & .015 & 117 \\
\cline { 2 - 4 } & N & 117 & 17 \\
\end{tabular}

*. Correlation is significant at the 0.05 level (2-tailed).

Note: $\mathrm{AL}=$ Active Learning \& $\mathrm{SE}=$ Students Classroom Engagement

The association between two variables is mentioned in table 4.3. The values of correlation between Active Learning Strategies and nursing students' classroom engagement are shown in above table. According to analysis of study, $\mathrm{p}$ value was .015 and Pearson correlation value of active learning strategies and nursing students' engagement was .225. It indicates that there is an association between the use of active learning strategies and classroom engagement of nursing students $(r=.225, \mathrm{p}<0.05)$. The $\mathrm{p}$ value is less than 0.05 which is an evidence to reject the null hypothesis and accept the alternate hypothesis. The correlation analysis of my study revealed that use of active learning strategies in classroom environment has an association with nursing students' classroom engagement.

\section{Discussion}

The correlation analysis of my study revealed that use of active learning strategies in classroom environment has an association with nursing students' classroom engagement. The Pearson correlation value was .225. findings from another study supported the link of student's engagement with active teaching-learning strategies, workload, motivation and achievement. Pearson correlation value was .5737 which is an evidence of significant positive relationship between students classroom engagement and the use of active teaching-learning strategies (Arjomandi, Seufert, O'Brien, \& Anwar, 2018).

Active learning strategies were found to be effective to enhance nursing student's participation in classroom and their learning outcomes. The results of my study were same as another study which showed that use of active learning strategies helped 179 nursing students to increase their participation in classroom environment and reduce the resistance for students involvement (Nguyen et al., 2017).

The present study findings showed the positive association of active learning strategies and students' perceptions with classroom engagement of nursing students. Results from another study provided evidence when students were taking notes, actively listening to the lecture, or working in groups and participate in discussions; they tend to be more engaged and pay more attention in the class. Thus, indirect relationship between the seating arrangements, student practices, perceptions and active learning strategies was found on learning and students 
classroom engagement (Shernof et al., 2017).

\section{Conclusion}

The present study examined the association of the use of active learning strategies and classroom engagement of nursing students of Lahore School of Nursing, The University of Lahore. It is inferred that nursing students who use active learning strategies are more engaged in classroom learning environment. The results indicated that nursing students meaningful processing, participation and focused attention in classroom environment is influenced by active learning activities and their perception of active learning in classroom. Statistical $p$ value of correlation between two these variables was $.015(\mathrm{p}<0.05)$ and Pearson correlation value was .225 which showed that there is a significant positive association or correlation between the use of active learning strategies and classroom engagement of nursing students. The study concluded that active teaching learning strategies in classroom environment can enhance nursing students overall engagement and learning outcome.

\section{Limitations and Recommendations}

The sample size was limited to 117 nursing students between 16-35 years of age which is not a true representative of knowledge of all nursing students of Lahore, Pakistan. Hence, generalization is possible only to the selected settings. Duration of study was short. Due to time constraint and the sample availability a convenience sampling technique was used in the present study. The study failed to control other variables such as teaching styles, classroom size and teachers' perception of active learning strategies that can influence the classroom engagement of students.

The same study could be conducted with a large sample size and more than two nursing programs to generalize the results. The study can be conducted in different setting with similar instruments and variables. An experimental and control group study can be done to identify the difference between active and passive classroom learning environments with similar settings. Further study to measure the faculty behaviors, teaching styles and perception of active learning strategies that promote engagement in the classroom would allow for comparison of student and instructor perceptions and increase the validity of the measurement of active learning environments.

\section{References}

Abdullah, Z., \& Jong, H. (2014). The relationship between communication satisfaction and teachers' job satisfaction in the Malaysian primary school. Asian Journal of Humanities and Social Sciences (AJHSS), 2(2), $58-71$.

Akhtar, S., Hussain, M., Afzal, M., \& Gilani, S. A. (2018). Barriers and Facilitators for Execution of Nursing Process among Nurses from Medical and Surgical Wards in a Public Hospital Lahore. International Journal of Social Sciences and Management, 5(3), 170-186.

Arjomandi, A., Seufert, J., O'Brien, M., \& Anwar, S. (2018). Active Teaching Strategies and Student Engagement: A Comparison of Traditional and Non-Traditional Business Students. e-Journal of Business Education and Scholarship of Teaching, 12(2), 120-140.

Carr, R., Palmer, S., \& Hagel, P. (2015). Active learning: The importance of developing a comprehensive measure. Active Learning in Higher Education, 16(3), 173-186.

Cavanagh, A. J., Chen, X., Bathgate, M., Frederick, J., Hanauer, D. I., \& Graham, M. J. (2018). Trust, growth mindset, and student commitment to active learning in a college science course. CBE-Life Sciences Education, 17(1), ar10.

D’Souza, M. S., Isac, C., Venkatesaperumal, R., Nairy, K. S., \& Amirtharaj, A. (2014). Exploring nursing student engagement in the learning environment for improved learning outcomes. Clin Nurs Stud, 2(1).

Gregg, S. R., \& Twibell, K. R. (2016). Try-it-on: experiential learning of holistic stress management in a graduate nursing curriculum. Journal of Holistic Nursing, 34(3), 300-308.

Hampton, D., \& Pearce, P. F. (2016). Student engagement in online nursing courses. Nurse educator, 41(6), 294298.

Hudson, K. F. (2015). Nursing student engagement: Student, classroom, and clinical engagement. International Journal of Nursing, 4(1), 44-52.

Kirschner, P. A. (2015). Do we need teachers as designers of technology enhanced learning? Instructional Science, 43(2), 309-322.

Malik, R. H., \& Rizvi, A. A. (2018). Effect of Classroom Learning Environment on Students' Academic Achievement in Mathematics at Secondary Level. Bulletin of Education and Research, 40(2).

Miller, C. J., \& Metz, M. J. (2014). A comparison of professional-level faculty and student perceptions of active learning: its current use, effectiveness, and barriers. Advances in physiology education, 38(3), 246-252.

Nguyen, K., Husman, J., Borrego, M., Shekhar, P., Prince, M., Demonbrun, M., \& Waters, C. (2017). Students' expectations, types of instruction, and instructor strategies predicting student response to active learning. International Journal of Engineering Education, 33(1), 2-18. 
Oermann, M. H. (2015). Technology and teaching innovations in nursing education: Engaging the student. In: LWW.

Popkess, A. M. (2010). The relationship between undergraduate, baccalaureate nursing student engagement and use of active learning strategies in the classroom.

Rands, M. L., \& Gansemer-Topf, A. M. (2017). The room itself is active: How classroom design impacts student engagement. Journal of Learning Spaces, 6(1), 26.

Rocher, A. R. d. (2018). Active learning strategies and academic self-efficacy relate to both attentional control and attitudes towards plagiarism. Active Learning in Higher Education, 1469787418765515.

Sattar, A. A., Kouar, R., \& Gillani, S. A. (2018). Exploring Nursing Students Engagement in Their Learning Environment. American Journal of Nursing Research, 6(1), 18-23.

Sharma, R. (2017). Emerging innovative teaching strategies in nursing. JOJ Nurs Health Care, 1(2).

Shernof, D. J., Ruzek, E. A., Sannella, A. J., Schorr, R. Y., Sanchez-Wall, L., \& Bressler, D. M. (2017). Student engagement as a general factor of classroom experience: Associations with student practices and educational outcomes in a university gateway course. Frontiers in psychology, 8, 994.

Ul Huda, S., Ali, T. S., Nanji, K., \& Cassum, S. (2016). Perceptions of Undergraduate Nursing Students Regarding Active Learning Strategies, and Benefits of Active Learning. International Journal of Nursing Education, 8(4), 193-199. 